\title{
Determination of Periodontal Status and Smoking Habits with CPITN Index
}

\author{
Ebru Saribas ${ }^{1}$, Filiz Acun Kaya ${ }^{1}$, Arzum Guler Dogru' ${ }^{1}$, Tuba Talo Yildirim² \\ ${ }^{1}$ Dicle University, Faculty of Dentistry, Department of Peridontology, Diyarbakir, Turkey \\ ${ }^{2}$ Firat University, Faculty of Dentistry, Department of Peridontology, Elazig, Turkey
}

\section{Correspondence:}

Dr. Ebru SARIBAS

Dicle University, Faculty of

Dentistry, Department of

Peridontology, 21280, Diyarbakir,

TURKEY.

e-mail:ebrusaribas@yahoo.com

Received 24 February 2017

Accepted 13 June 2017

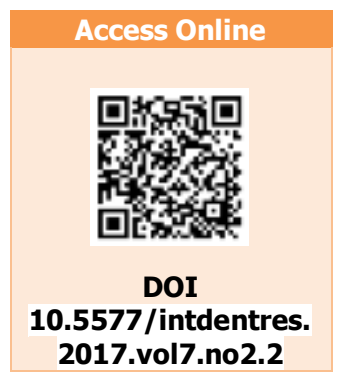

\section{Introduction}

It is assumed that, the microbial dental plaque was the the most important etiological factor which CPITN

\begin{abstract}
Aim: Periodontal diseases are a major worldwide and is considered to be one of the most common oral pathologies. A large portion of periodontal pathologies are affected by a variety of factors genetic, socio-economic status, smoking, oral hygiene and lifestyle. The relationship between smoking and periodontal disease attracting more and more interest in the last 10-15 years. This study was planned to determine whether there is a relationship between smoking habits and periodontal status.

Methodology: In this study, 372 individuals were evaluated between the ages 12-79. These individuals divided into 7 groups according to age, including 12-19, 20-29, 30-39, 40-49, 50-59, 6069 , and 70-79. CPITN scores and whether or not cigarette smoking habits of all individuals were recorded. Daily cigarette consumption was evaluated 0, occasionally, 1-10, 11-20 and more than 20. Results: In our study, no significant statistical difference was found between the age groups and gender $(p>0.05)$. There is a relationship proportional to the age and periodontal disease $(p<0.05)$. Periodontal status of individuals who smoke analyzed, although individuals who smoke have higher periodontal scores, statistically significant relationship was not found between the two groups.

Conclusions: Examined the periodontal status of the individuals included in the study, there is no difference between smokers and nonsmokers with individuals, despite the periodontal scores were higher in smokers. It is suggested that oral hygiene education would be effective in the rate of smoking and periodontal health.
\end{abstract}

Keywords: Periodontal diseases, smoking, epidemiologic methods,

How to cite this article: Saribas E, Acun Kaya F, Dogru AG, Talo Yildirim T. Determination of periodontal status and smoking habits with CPITN index. Int Dent Res 2017;7:26-31. disrupts oral and dental health. Dental plaque, which has a complex structure, accumulates on the surface of the teeth and can not be removed efficiently from the teeth. As a result of this, microorganisms inside of plaque and their toxic products cause oral health 
deterioration. Microbial dental plaque is accepted as the primary factor in the etiology, but also it has been demonstrated that, factors such as the individuals' age, gender, race, habits, systemic disease, socio-economic and cultural conditions effected the oral and dental health $(1,2)$.

Periodontal diseases are considered to be one of the most common and worldwide oral pathologies. Severe chronic periodontitis is seen 5$20 \%$ of the adult population. Periodontal diseases may affect the quality of life in adults and are associated with both oral and systemic health. A large portion of periodontal pathologies are affected by a variety of factors, including genetic, socioeconomic status, smoking, oral hygiene and lifestyle (2).

The studies have shown that, smoking is the most important risk factor associated with the prevalence and severity of periodontal disease. In the studies, it has been reported increase in the prevalence and severity of periodontitis, more marginal bone loss, deeper periodontal pockets, more severe tooth attachment loss, furcation involvement in more teeth in adult smokers $(3,4)$.

The association of smoking with periodontal disease called more attention in the last $10-15$ years (5). Smoking, which is reported as major and enviromental risk factor for periodontitis, has a negative effect on the local and systemic host defense systems $(3,6,7)$. Locally, vasoconsructive effect of nicotine in cigarette on the blood vessels causes slow down of gingival blood flow and possibily decrease in number of cells, the amount of oxygen and other blood contents coming to gingiva and decrease in the ability to remove tissue degradation products. Systemically, it blocks neutrophil function the peripheral blood and reduces the production of antibodies (6). The studies on the amount of cigarettes smoked and periodontal disease detected the relationship between amount and prevalence and severity of periodontitis. This relationship is between the prevalence of moderate and severe periodontal disease with the number of cigarettes smoked per day and smoking years (8). Periodontal diseases are often chronic nature and, more specifically known for the adult population. Although, smoking is more thought for the middleaged and older adults, in the studies, it has been shown that, the prevelance became increasing level among the teenagers and young adults (4). Maintain the existing oral health, stopping the consisting disease, re-restoring and maintain the health, the most important pre-condition is to perform regular, adequate and accurate oral care. Knowledge about the teeth and periodontal condition is important for the planning of necessary preventive and therapeutic interventions (9). Therefore, in dentistry, taking protective and preventive measures and the opinion of moving treatment services to conservative methods to keep the teeth in the mouth before oral and dental health deterioration gained the importance (1).

Several index systems were identified for the determination of the severity and necessary treatment of periodontal diseases. CPITN, one of these index, is widely used in order to predict the condition and requirements of the treatment of periodontal diseases (10). In our study, we aimed to determine whether there is a relationship between smoking habits and periodontal status using CPITN index.

\section{Materials and Methods}

The study group is consisted with 372 individuals; 207 men, 165 women, admitted to Dicle University Faculty of Dentistry, Department of Periodontology. These individuals were divided into 7 groups according to age such as: 12-19, 20-29, 30-39, 40-49, 50-59, 60-69, and 70-79. Patients filled a questionnaire on age, gender, smoking status. Clinical examinations were made according to the criteria of CPITN. Mouth was divided into 6 sectant, the teeth in the areas with so less teeth that can not be evaluate, have been included in the neighbour sectant.

CPITN scores:

Code 0: No periodontal disease (healthy periodontium).

Code 1: Bleeding observed during or after probing.

Code 2: Dental calculus and iatrogenic factors.

Code 3: 3.5 to $5.5 \mathrm{~mm}$ shallow pockets.

Code 4: Pathological pocket $6 \mathrm{~mm}$ and more in depth.

According to CPI scores, 3 treatment categories were determined:

TN1: Only oral hygiene education.

TN2: TN1+ surface teeth cleaning, correction of incorrect restorations

TN3: TN1+TN2+ Complicated treatment (surgical treatment)

Daily cigarette consumption 20 was evaluated as 0 , occasionally, 1-10, 11-20 and more than 20 . These individuals included in the study were informed about the study and the patient consent forms were taken.

\section{Statistical Analysis}

In this study, Pearson's Chi-square test was used to evaluate the relationships between the parameters and $p<0.05$ was accepted as the level of error for the evaluation of the results. 
All statistical analyses were performed using the SPSS software (ver. 20.0).

\section{Results}

The distributions of individuals according to age and gender are given in Table 1. A total of 372 individuals; 207 male and 165 female, were included in the study. There was no statistically significant difference between the age groups in terms of gender ( $p>0.05$, Table 1).

In Table 2, the incidences of CPITN scores of individuals according to age groups were given. Between the groups, Code 2 score, which dental calculus and iatrogenic factors were detected, has a maximum percentage. In all groups, there was a relationship between periodontal health and age, and this increase was statistically significant $(p<0.01$, Table 2).

In Table 3, distribution of treatment needs according to age groups was presented. TN1 as maximum in the age group of 12-19. TN3 value value was observed as minumum in the age group of 20-29, as maximum in the age group of 70-79 ( $p$ $<0.01$. Table 3).

The frequency and number of smoking of individuals according to smoking status and the incidence of CPITN scores were given in Table 4. Code 3 value was 5.7 in non-smokers individuals. In the individuals smoking more than 20 per days, it was found to be 20.0. Although, periodontal scores of smokers were higher than non-smokers individuals, this difference was not statistically significant (Table 4).

Table 1: The distribution of individuals according to age and gender

\begin{tabular}{|c|c|c|c|}
\hline Age & Male & Female & Total \\
\hline $\mathbf{1 2 - 1 9}$ & 29 & 34 & $\mathbf{6 3}$ \\
\hline $\mathbf{2 0 - 2 9}$ & 80 & 65 & $\mathbf{1 4 5}$ \\
\hline $\mathbf{3 0 - 3 9}$ & 33 & 36 & $\mathbf{6 8}$ \\
\hline $\mathbf{4 0 - 4 9}$ & 34 & 18 & $\mathbf{5 2}$ \\
\hline $\mathbf{5 0 - 5 9}$ & 25 & 8 & $\mathbf{3 3}$ \\
\hline $\mathbf{6 0 - 6 9}$ & 3 & 4 & $\mathbf{7}$ \\
\hline $\mathbf{7 0 - 7 9}$ & 3 & 0 & $\mathbf{3}$ \\
\hline Total & $\mathbf{2 0 7}$ & $\mathbf{1 6 5}$ & $\mathbf{3 7 2}$ \\
\hline
\end{tabular}

Table 2: The incidence of CPITN scores of individuals according to age groups (\%)

\begin{tabular}{|c|c|c|c|c|c|c|}
\hline Age & $\begin{array}{c}\text { Number of } \\
\text { individuals } \\
\text { with teeth }\end{array}$ & Code 0 & Code 1 & Code 2 & Code 3 & Code 4 \\
\hline $\mathbf{1 2 - 1 9}$ & 64 & 26.6 & 28.1 & 39.1 & 4.7 & $\mathbf{1 . 6}$ \\
\hline $\mathbf{2 0 - 2 9}$ & 145 & 11.7 & 29.0 & 51.0 & 6.9 & $\mathbf{1 . 4}$ \\
\hline $\mathbf{3 0 - 3 9}$ & 68 & 16.2 & 25.0 & 45.6 & 10.3 & $\mathbf{2 . 9}$ \\
\hline $\mathbf{4 0 - 4 9}$ & 52 & 13.5 & 25.0 & 40.4 & 19.2 & $\mathbf{1 . 9}$ \\
\hline $\mathbf{5 0 - 5 9}$ & 33 & 15.2 & 21.2 & 42.4 & 18.2 & $\mathbf{3 . 0}$ \\
\hline $\mathbf{6 0 - 6 9}$ & 7 & 14.3 & 0 & 42.9 & 14.3 & $\mathbf{2 8 . 6}$ \\
\hline $\mathbf{7 0 - 7 9}$ & $\mathbf{3}$ & $\mathbf{0}$ & $\mathbf{0}$ & $\mathbf{3 3 . 3}$ & $\mathbf{3 3 . 3}$ & $\mathbf{3 3 . 3}$ \\
\hline
\end{tabular}


Table 3: The incidence of treatment needs of individuals according to age groups (\%).

\begin{tabular}{|c|c|c|c|c|}
\hline Age & $\begin{array}{c}\text { Number of } \\
\text { individuals with } \\
\text { teeth }\end{array}$ & TN1 & TN2 & TN3 \\
\hline $\mathbf{1 2 - 1 9}$ & 64 & 54.7 & 43.8 & $\mathbf{1 . 6}$ \\
\hline $\mathbf{2 0 - 2 9}$ & 145 & 40.7 & 43.8 & $\mathbf{1 . 4}$ \\
\hline $\mathbf{3 0 - 3 9}$ & 68 & 41.2 & 55.3 & $\mathbf{2 . 9}$ \\
\hline $\mathbf{4 0 - 4 9}$ & 52 & 38.5 & 59.6 & $\mathbf{1 . 9}$ \\
\hline $\mathbf{5 0 - 5 9}$ & 33 & 36.4 & 61.6 & $\mathbf{3 . 0}$ \\
\hline $\mathbf{6 0 - 6 9}$ & 7 & 14.3 & 57.2 & $\mathbf{2 8 . 6}$ \\
\hline $\mathbf{7 0 - 7 9}$ & $\mathbf{3}$ & $\mathbf{0}$ & $\mathbf{6 6 . 6}$ & $\mathbf{3 3 . 3}$ \\
\hline
\end{tabular}

Table 4: The frequency and number of smoking of individuals and the incidence of CPITN scores (\%).

\begin{tabular}{|c|c|c|c|c|c|c|}
\hline $\begin{array}{c}\text { Cigarette } \\
\text { smoking }\end{array}$ & $\begin{array}{c}\text { Number of } \\
\text { individuals }\end{array}$ & Code 0 & Code 1 & Code 2 & Code 3 & Code 4 \\
\hline $\mathbf{0}$ & 241 & 17.0 & 27.4 & 44.8 & 7.5 & $\mathbf{3 . 3}$ \\
\hline Occasionally & 24 & 12.5 & 33.3 & 45.8 & 8.3 &. $\mathbf{0}$ \\
\hline $\mathbf{1 - 1 0}$ & 39 & 15.4 & 20.5 & 48.7 & 12.8 & $\mathbf{2 . 6}$ \\
\hline $\mathbf{1 1 - 2 0}$ & 52 & 11.5 & 21.2 & 46.2 & 19.2 & $\mathbf{1 . 9}$ \\
\hline $\mathbf{2 0}>$ & $\mathbf{1 5}$ & $\mathbf{6 . 7}$ & $\mathbf{2 6 . 7}$ & $\mathbf{4 6 . 7}$ & $\mathbf{2 0 . 0}$ & $\mathbf{. 0}$ \\
\hline
\end{tabular}

\section{Discussion}

Epidemiological studies on oral and dental health reveals the importance of the problem of dental health in our society. Protective measures that should be taken for dental health and indicating the need and importance of periodontal health plays an important role in raising awareness of the society. Dental problems can be minimized and more effective results can be obtained with giving information about tooth decay and dental plaque to the community, regular brushing and dental care. It has been emphasized that, in the basic and other sudies on the care of the mouth, for regular and adequate oral hygiene, the teeth should be brush at least 2 times a day and cleaned with dental floss once a day. Tooth decay and periodontal disease is observed at the rate of $96 \%$ in Turkish population (9). In Turkey, it has been seen that with the evaluation of the results of epidemiological studies performed in order to determine oral health, the importance giving to tooth and gingival health was less and tooth loss due to tooth decay and Periodontal diseases was very high levels. Of the factors involved in the etiology of tooth loss and identification of measures that can be taken is of great importance.

It has been proposed that to evaluate the oral and dental health of patients between the ages of 12-79 admitted Dicle University Faculty of Dentistry Periodontology Clinic by considering all of data.

In the epidemiological studies on periodontology; the indices that do not cause large differences between practitioners and applied easily are preferred. CPITN index developed by WHO is used commonly for these reasons $(4,10)$. Almas et al (11) have reported that, there was no direct relation 
between CPITN scores and plaque and gingival index. On the other hand, they emphasized that, there was a relationship between CPITN and papilla bleeding and pocket depth index. It has been emphasized that, CPITN was weak guide for determining the gingivitis, but a good indicator for chronic periodontal disease. Also, it was originally proposed as an appropriate estimation of disease in large epidemiological surveys and has contributed to an understanding of the epidemiology of periodontal disease on a global level (12). In our study, the relationship between periodontal and smoking habits of individuals was investigated by using the CPITN index system.

In our study, it has been detected that, periodontal disease findings increased depending on age. This finding is consistent with the findings of many studies performed before on this subject (1315). Researchers have reported that, periodontal diseases were more common in older individuals, and these individuals had poor oral hygiene (15-18). In middle-aged and elderly individuals, moderate loss of attachment was found highly, severe loss of attachment was less and similar results could be said about bone loss (16).

Tobacco smoking, mostly in the form of cigarette smoking, is recognized as the most important environmental risk factor in periodontitis (3). It has been estimated that about a third of the male adult global population smokes. Among the young, one in five smokes worldwide (12). Individuals who smoke for a long time can lose their lives due to systemic diseases seen in connection with smoking. Therefore, it is seen that, quitting smoking and even never starting is the most practical way in order to prevent periodontal disease / tooth loss, tobacco-related diseases and improve the quality of life $(19,20)$.

In a study from the United States, the frequency of smoking in older individuals between the ages of $50-70$ has been identified as $19 \%$. In another study from Mexico, in individuals aged 60 and over, smoking prevalence was detected as $13 \%$ (15). Baelum et al (17) in their study performed in Thailand, have detected that the rate of smoking between the ages of $30-39$ was $39 \%$, between the ages of $50-59$ was $45 \%$. Axelsson et al (21) have reported that, approximately $30 \%$ of the individuals participating in the study were smokers, but the distribution was not equal in terms of age and sex. In the study performed by Eren et al (15) it has been come out that, $25 \%$ of individuals included in the study smoked at any period of their life. In a study performed in order to elucidate the prevalence of smoking of young people in Turkey, this rate was detected as $30.6 \%$ (20). The rate of smoking among individuals included in our study was detected to be $35 \%$.
In several epidemiologic studies, it has been reported that, the effect of smoking on young individuals was similar to older ones. Researchers concluded that, smoking was a risk factor for periodontal diseases from an early age and will double the likelihood of periodontitis occurring by the mid-twenties and associated with accelerated periodontal destruction among young adults $(2,4$, 17, 22). However, there are some studies which do not find the relationship between smoking and periodontal destruction in young individuals (23-25). Yücesoy and Balos (22) have reported that, smoker and nonsmoker groups was in need of a high rate of initial periodontal therapy, but in smokers group, the need for treatment increased more. In another study it was reported that, poor periodontal health knowledge was associated with low-level treatment need and smoking was associated with high-level treatment need. Hence, it is possible to decrease community need for periodontal treatment with the elimination of acquired risk factors of periodontitis. (26).

\section{Conclusions}

The periodontal status of the individuals included in the study were examined and it has been detected that, the scores of the individuals who smoke was higher but there was no statistically significant relationship. This result was thought to be related to the number of individuals included in the study. Further studies should be focused on determining of individual treatment needs and epidemiological studies conducted on larger groups.

\section{Acknowledgments}

The authors deny any conflicts of interest related to this study.

\section{References}

1. Altun C, Güven G, Başak F, Akbulut E. Evaluation of children in the age group of 6 to 11 with respect to oraldental health Gulhane Med J. 2005;47(2):114-8.

2. Zini $A$, Sgan-Cohen HD, Marcenes W. Socio-economic position, smoking, and plaque: a pathway to severe chronic periodontitis. J Clin Peridontol 2011;38:229-35. Crossref

3. Palmer RM, Wilson RF, Hasan AS, Scott DA. Mechanisms of action of environmental factors - tobacco smoking. J Clin Peridontol 2005;32 (Suppl. 6):180-95. Crossref

4. Vered $Y$, Livny A, Zini A, Sgan-Cohen HD. Periodontal health status and smoking among young adults. J Clin Periodontol 2008; 35: 768-72. Crossref 
5. Zee K-Y. Smoking and periodontal disease. Australian Dental Journal 2009;54:(1 Suppl):44-50. Crossref

6. Erdemir EO, Duran İ, Çelik İ. The effect of smoking on phagocytic activity of peripheral PMN in patients with chronic periodontitis. Cumhuriyet Dental Journal 2003; 6(1):1-5.

7. Thomson WM, Broadbent JM, Welch D, Beck JD, Poulton R. Cigarette smoking and periodontal disease among 32-yearolds: a prospective study of a representative birth cohort. J Clin Periodontol 2007;34:828-34. Crossref

8. Erdemir EO. Cigarette smoking and periodontal disease. Hacettepe Dental Journal. 2005;29(4):35-41.

9. Demirer S, Çatalbaş B, Gelgör İE, Görür T, Karşıyaka M. The comparison of oral health knowledge oral care and periodontal status in preorthodontic treatment between children and their parents: Preliminary study. SU Dental Journal, 2010;19:26-34.

10. Bozkurt FY, Fentoğlu Ö, Kıran M. The evaluation of the clinical oral conditions in the adolescents from the urban and rural sites of Isparta. Turkiye Klinikleri J Dental Sci 2002;8(1):25-30.

11. Almas K, Bulman JS and Newman HN: Assessment of periodontal status with CPITN and conventional periodontal indices. J Clin Periodontol 1991;18:654-9. Crossref

12. Gautam DK, Jindal V, Gupta SC, Tuli A, Kotwal B, Thakur R. Effect of cigarette smoking on the periodontal health status: A comparative, cross sectional study. J. Indian Soc Periodontol 2011;15(4):383-7. Crossref

13. Çanakçı V, Akgül M, Tezel $A$. The determination of the periodontal status and the treatment needs in adults by means of clinical and radiographic findings in addition to CPITN index. A. U. Journal of Dental Faculty 1999;9(2):1924.

14. Yetkin Ay A, Çağlar F. The investigation of the relationshıp between obesity and periodontal status with anthropometric and bioelectric impedance methods. J Dent Fac Atatürk Uni. 2010;20(3):139-144.

15. 1Eren G, Köse T, Atilla G. Determining the oral health status and oral hygiene habits of the elderly. SU Dental Journal 2011;20:84-92.

16. Locker $\mathrm{D}$, Slade GD, Murray $\mathrm{H}$. Epidemiology of periodontal disease among older adults: a review. Periodontology 2000, 1998;16:16-33. Crossref

17. Baelum V, Pisuithanakan $S$, Teanpaisan $R$, Pithpornchaiyakul W, Pongpaisal S, Papapanou PN, Dahlen G, Fejerskov O. Periodontal conditions among adults in Southern Thailand. J Periodont Res 2003;38:156-63. Crossref

18. Boehm TK, Scannapieco FA. The epidemiology, consequences and management of periodontal disease in older adults. J Am Dent Assoc 2007;138: 26S-33p. Crossref

19. Karasu G. Determination of periodontal status in elderly individuals and oral care habits, Journal of Ege University Faculty of Dentistry Periodontology graduation thesis, 2007.

20. Okamoto Y, Tsuboi S, Suzuki S, Nakagaki H, Ogura Y, Maeda K, Tokudome S. Effects of smoking and drinking habits on the incidence of periodontal disease and tooth loss among Japanese males: a 4-yr longitudinal study. ] Periodont Res 2006;41:560-6. Crossref

21. Axelsson P. Paulander J. Lindhe J: Relationship between smoking and dental status in 35- 50-, 65-, and 75-year-old individuals. J Clin Periodontol 1998;25:297-305. Crossref

22. Yücesoy V, Baloş K. Assessment of periodontal status and treatment needs in smokers and non-smokers. Journal of Gazi University Faculty of Dentistry 1998;15:81-7.

23. Muller, H. P., Stadermann, S. \& Heinecke, A. Bleeding on probing in smokers and non-smokers in a steady state plaque environment. Clinical Oral Investigations 2001;5:177-84. Crossref

24. Muller, H. P., Stadermann, S. \& Heinecke, A. Gingival recession in smokers and non-smokers with minima periodontal disease. J Clin Periodontol 2002;29:129-36. Crossref
25. Romao, C. \& Wennstrom, J. L. Periodontal conditions in a Swedish city population of adolescents: a comparison between smokers and never-smokers. Oral Health and Preventive Dentistry 2007;5:105-12.

26. Demirer S, Gürsoy UK, Ozdemir H, Erdemir EO, Uitto VJ. Periodontal health knowledge and smoking are associated with periodontal treatment need according to tooth brushing levels. West Indian Med J 2012;61(2):191-7. 